\title{
Situational liminality: Mis-managed consumer experience in liquid modernity
}

\author{
Michal Izak*
}

University of Lincoln, Business School Brayford Pool, Lincoln LN6 7TS, UK

\author{
KEYWORDS \\ Abduction; \\ Disambiguation; \\ Experience economy; \\ Experience \\ mismanagement; \\ Liquid modernity; \\ Overkill of experience; \\ Situational liminality; \\ Self-reflective inquiry
}

\begin{abstract}
The purpose of the paper is to explore experience economy events from an abductive interpetivist perspective. The empirical part of the study is based on the self-reflective anthropologic inquiry method. This study sets out to propose that the awkwardness and setback experienced by the client, customer or visitor, may generate his/her agency to establish a more clear-cut construction of the experiential framework. However, if attempted the disambiguation demands significant emotional and, sometimes, physical labour, typically not undertaken willingly, and potentially resulting in the subject's avoidance of exposure to similar experiences in future. Introducing the notion of 'situational liminality', the paper re-focuses the critical edge of inquiry away from agency-reducing aspects of experience economy, towards reflecting on their enforced, albeit not deliberate, agency-inducing consequences. By exploring the 'liquid' underpinnings of situational liminality, this study contributes to the ongoing discussion on liquid modernity in organizational context.
\end{abstract}

(C) 2014 Elsevier Ltd. All rights reserved.

\section{Introduction}

Given the third sector's preponderance in the developed world economies and Pine and Gilmore's (1999) widely acknowledged emphasis on the experiential aspect of service provision, experience economy is a topical issue for management theorists and practitioners. In this respect, services rendered in supermarkets, long distance trains, banks, post offices or food courts are expected to not only fulfil their basic functions (travel, communication, access to financial resources) but also go beyond them: enabling to relax, ensuring pleasant waiting time, providing satisfactory shopping experience or prompt and reliable exchange of information. However, while experience may be the neweconomic offering (Pine \& Gilmore, 1999),

\footnotetext{
* Tel.: +44 1522835692 .

E-mail address: mizak@lincoln.ac.uk.
}

this study will explore its dark side emerging due to frustration, confusion and despondency of clients, visitors or customers. Expecting to contribute new insights to critical research on experience economy, the study will explore the agency-inducing (rather than limiting) aspects of multifaceted failures to provide positive experience from the viewpoint of the recipient. Using the self-reflective inquiry, and in the spirit of abductive interpretivism, the paper will scrutinize the experiential framework for mis-managed experience introducing the notion of situational liminality for the potential benefit of organizational practitioners and theorists. Since Zygmunt Bauman's timely reflection on 'liquidity' of the modern world provides a suitable background for exploring the liminality in the experiential sphere of economic exchanges, the study attempts to endow the current discussions on liquid modernity in organizational context (e.g. Kociatkiewicz \& Kostera, 2014) with a new perspective and conceptual input. Before the empirical case studies are presented and discussed, the theoretical background of inquiry (liminality, experience economy 
and liquid modernity) is introduced and the methodology explained. The paper's contribution is captured through an abductive hypothesis the implications of which are discussed in the final part of the work.

\section{Theoretical context}

\section{Liminality}

The blurring of boundaries between organization and the outside world (Paulsen \& Hernes, 2003), other organizations (Tempest \& Starkey, 2004), as well as between work and private sphere (Hochschild, 1997), invite the reflection on the nowadays fleeting, liquid nature of social reality as such (Bauman, 2001). In 'liquid modernity' the constant 'uprootedness' of social actors and crossing the pre-established boundaries, be it in private or institutional arena, becomes the new norm (Bauman, 2000). This fluidity, not-belongingness to neither of the two spaces, institutions or groups, is increasingly perceived in terms of assuming the liminal status.

'Liminal' originally meant a threshold in the physical sense-the bottom part of a doorway that must be crossed when entering a building; its current meaning is typically psychological: "a threshold below which a stimulus is not perceived or is not distinguished from another" (OED, accessed on 17/ $06 / 12$ ). The notion of liminality was first introduced to the field of anthropology as 'a liminal period', the middle part of a ritual of marriage - the stage of transition following the 'separation' from the initial social context and preceding the 'reassimilation' into society upon the endowment of the new status (van Gennep, 1909/2004). This concept was further developed in the 1960s and 1970s by Turner (1967, p. 95), whose work focused on the 'social ambiguity' and 'structural invisibility' of the subject during the liminal period. The 'liminality' was perceived as the negation of "all positive structural assertions [and simultaneously], in some sense, the source of them all" (op. cit., p. 97). In a similar vein, Turner (1969, p. 95) asserts that 'liminal individuals' are "neither here nor there; they are betwixt and between the positions assigned and arrayed by law, custom, convention, and ceremony". Hence, liminality may be perceived as an anti-structure, but it may also become the source of the emerging structure, just as chaos may precede an order. Liminality appears where distinctions merge and blur (Turner, 1982), which is where the social ambiguity steps in-a lack of definition validating the social structure means that in the liminal phase people have no rights over others. This ambiguous social space is associated with freedom and creativity (Czarniawska \& Mazza, 2003). The liminal community can also appear, however, instead of identity, it will be mediated by 'the shared sense of alterity', which seems to be the uniting principle of 'the liminal organization' (ibid.). The latter may share all physical and legal boundaries with a 'proper' work organization, but, as Czarniawska and Mazza in their study of consultants' work indicate, its virtual space is experienced differently by different organizational actors (ibid.). The consultants may be perceived as originators of organizational ambiguity - not only the nature of their occupation (moving in and out), but also its results (the temporary suspension of, at least, some organizational mechanisms) contribute to the liminality of organizational space. The role of other organizational groups may be similar-e.g. the communities created by temporary workers (Garsten, 1999). Rottenburg interestingly extends the notion of liminality to include places-physical spaces (in this case: a café, which in the evening transforms into a bar and ends up as a discotheque), in which established categories work only temporarily, their validity is as transitory as are conceptualizations created by people involved in a given social context (2000). Hence the aporia created by the liminal space-classifications are impossible, just as much as avoiding the process of classifying (ibid.).

Liminality may be associated with the newly acquired freedom of expression, improvisation, manipulation (Zabusky \& Barley, 1997) and creativity (Clegg, Kornberger, \& Rhodes, 2004) as well as with the suspension of institutional routines of rationality, which creates the room for political agendas, such as 'issue selling', building the 'power map' and identifying allies (Sturdy, Schwartz, \& Spicer, 2006). Using the dialogical perspective, it may also be perceived as contributing to identity reconstruction of people in organizations (Beech, 2011). However, it is also argued that liminality can easily be turned into an unsettling experience (Newell, Tansley, \& Wagner, 2008) or at least one involving uncertainty regarding the definition of the given social context (Rottenburg, 2000). Cunha and CabralCardoso (2006) and Guimarães-Costa and Cunha (2009) underlined the uncertain and unsettling aspect of liminality by examining the illegality of actions undertaken within organizations and the roles of international managers, respectively. In both cases the discrepancy between general rules and their application in specific situations evoked the dilemma inducing certain activity on the part of actors involved: the decision to be made. The unsettling and agency-inducing aspects of liminality will be further explored in the current study.

\section{Experience economy}

The basic rationale behind the concept of experience economy is that not only did agricultural and industrial economies fail to deliver unique goods, but also services are increasingly perceived by customers as an undifferentiated mass, much akin to such products as jean trousers or bread. However, expertly staging the customer's experience enables differentiating between similar goods and services-after all the subtitle of Pine and Gilmore's (1999) seminal book reads "work is a theatre and every business a stage".

While building the customer relationship through offering an array of products and services was once perceived as viable strategy (Peppers \& Rogers, 1993), such 'relationship' appears to remain fragile unless emotional linkages are made (Johnson \& Grayson, 2005). Hence, the affective aspects of service experience (such as 'trust' see Hawes, Mast, \& Swan, 1989; Swan, Trawick, Rink, \& Roberts, 1988) are increasingly deemed crucial to customer-to-business relationships (Fournier, Dobscha, \& Mick, 1998) and become a standalone focus of empirical studies (Johnson \& Grayson, 2005). Even if the experience side of consumption was certainly not an entirely new discovery (e.g. see Laverie, Kleine, \& Schultz-Kleine, 1993), for Pine and Gilmore experiences become a distinct economic offering-as distinct from services as services are from goods (1998). In the experience economy value for the consumer no longer comes from the product (material) or service (material or immaterial); it comes from the experience derived from consuming them. 
The primary goal of experience economy settings is facilitating the consumer's experience (Kociatkiewicz \& Kostera, 2012). Naturally, the latter is, must be, immaterial and subjective. Therefore, consumption becomes closely linked to these 'ephemeral instances' (Johansson \& Näslund, 2009) by which organizations produce engagement-feelings and emotions (Fineman, 1999). The consumption of experience takes place in multiple new settings, 'cathedrals', enchanted through the means of spectacle (Debord, 1967/1995), in which consumers are enticed to practice their consumerist religion (Ritzer, 1999).

While strategic level inquiries into customer experience creation recognize a relative scarcity of research exploring customer experience 'in depth' (Verhoef et al., 2009), this approach is predominantly inscribed in the functionalist paradigm: the focus is on improving and the vocabulary is that of 'impact' and 'measurement' (e.g. Gentile, Spiller, \& Noci, 2007; Novak, Hoffman, \& Yung, 2000). On the other hand, from the critical viewpoint, the imposition of control, compliancy and enforced constriction of consumer behaviour are oft-indicated features of these consumer-oriented settings (e.g. Baudrillard, 1998; Raz, 2003). However, the current study will focus on these instances in which organizational designs not only fail to effectively deliver feelings and emotions sought after by the consumers, simultaneously failing to 'entrap' the participants in these aspects of experience economy which attract the attention of critical theorists, but ineptly trying to do so potentially occasion an attitude of an active aversion. ${ }^{1,2}$

\footnotetext{
${ }^{1}$ Arguably, such cross-sectional concepts as 'feelings' and 'emotions' have been variously defined and even occasionally dispensed as untenable (Duffy, 1941). In this paper emotions and feelings are approached from the perspective of 'the new social theory of emotion' (Hochschild, 1983) which is widely applied in the field of experience economy. This theory combines the biologic (organismic) and societal (interactivist) models, with a strong emphasis on the latter. The mechanism in which certain biological inputs signal particular emotions to be expressed, is affected by the sociallyderived rules deciding the meaning of particular input. This 'signal' is a 'feeling'-an emotional state which points towards specific reaction. In other words, Hochschild is positing an interactional view of biologically derived emotion (informed by feeling) which one could approach as a potentiality which is shaped by the social (Clarke, 2006). In a similar vein, other psychological concepts used in this paper are defined from the perspective of social psychology explaining the biological reaction through social conditioning. Hence 'aversion' is both a physiological and emotional response to a stimulus that indicates that an object or situation 'does not correspond' to ones' rendition of socially desirable context and thus should be avoided. Psychological 'attitudes' are perceived as socially formed 'settled ways of thinking' (OED, accessed on 17/04/14) and 'agencyinducing consequences', discussed later on, refer to emotional as well as physiological aftermath of an active aversion.

2 The theme of organizational performance and underperformance is commonly discussed in terms of indispensable resources (Barney, 1991) and features which effective and successful organizations (Peters \& Waterman, 1982) or more explicitly organizational cultures (Barney, 1986) must possess in order to be successful (Sanchez, Jimenez, Carnicer, \& Perez, 2007Lin \& Chen, 2007Prašnikar, Ferligoj, Cirman, \& Valentincic, 1999). The common element of these approaches is their functionalist foundation. In the current study a different, phenomenological notion of 'effectiveness' is used-one which emphasizes understanding of its context rather than seeking for the solution to the problem.
}

Therefore, the present research distances itself from the functionalist approaches and advances the ongoing debates on experience economy by re-focusing the critical edge of inquiry away from restricting, control imposing and other agency-reducing frameworks, towards reflecting on their enforced, if not deliberate, agency-inducing consequences. Scrutinizing such contexts from the viewpoint of mental and physical effort demanded from participants (not sought-for by the designers of the particular experiential framework) may produce further insights into socially relevant themes, such as the attitudes of avoidance displayed by social actors (e.g. Kivlighan, Lo Coco, \& Gullo, 2012).

In this regard, the notion of situational liminality - an unintended aspect of experience economy events - is introduced to account for the position of ambiguity which the consumer is compelled to overcome.

Six real-life case studies will be adduced in order to: inquire into these aspects which intersubjectively appear common (1); explore different subjective facets of mismanaged experience (2); discuss the agency-generating effects of such interactions (i.e. decisions made and actions undertaken by the subjects) (3); as well as consider their plausible psychological implications (4). Drawing on the author's reformulation of the frequently invoked notion of liminality, the study will conclude with an abductive hypothesis consolidating the discussion of these points of interest.

\section{Methodological framework}

In this study organizations and organizational experiences of individuals are discussed within the context of the narrative approach (Boje, 2001). The collected field reports form narratives and result in multiple stories (Gabriel, 2000) or narratives of personal experience (Simpson, 2010), which may constitute a worthwhile reflection of different attempts at managing organizational reality (Czarniawska, 1997). Kociatkiewicz and Kostera (2010, p. 263) stress the performative aspect of experience economy events and suggest that the use of narrative methods "highlights the intangibility and fleeting nature of experience economy organizing". Therefore, similarly to theirs (ibid.), the current study employs the collection of ex-post written narratives which recall the author's experiences in the field. This self-reflective anthropologic inquiry enables maintaining the ability to be surprised by what one observes (Kociatkiewicz \& Kostera, 1999), and therefore preserve the fleeting subjective aspect of the mismanaged experience.

While the subjective element is indispensable in qualitative studies it does not render them less reliable (Stenbacka, 2001) or valid (Golafshani, 2003). Both reliability and validity are assured in the interpretive paradigm (Mishler, 2000; Lincoln \& Guba, 1985) through their trustworthiness (Seale, 1999) and capacity to facilitate the understanding of a situation (Eisner, 1991). Naturally, one of the alternatives to using the self-reflective method would be the analysis of customer's feedback, for instance through blogs and various social media. This approach has been tried and tested, however, it occurred ill-suited for the purposes of the study due to its possible overemphasis on either dry facts or general feelings rather than the thick description-typically applied when an attempt to understand the specificity of a given ethnographic context is made (Geertz, 1973). 
Since my goal is to discuss the situationally-induced experience, it entails that the reader must be able to experientially relate to the described situations. While the aim of interpretivist research is to approximate the worlds of others as if they were (almost) our own (Van Maanen, 1979), I attempt to render my world accessible to others through thick description. What, I believe, makes the descriptions 'thick' in this case, is the experiential load which they carry expressed through feelings and emotions, such as irritation, relief, anger, awkwardness, etc. Admittedly, it is not socio-cultural 'thickness' (cf. Geertz, 1973), but I believe it only makes sense to apply a theoretical concept in the context of research if it facilitates achievement of the study' aim - in this case the emotional layer of experience has paramount importance. Hence, although the basic dynamics of interpretivist research are preserved, the study cannot yield itself to some interpretivist limitations and distinctions. First of all, similarly to Kociatkiewicz and Kostera (1999), I perceive the boundary between objectivism and subjectivism as a constraint which can be overcome-clearly, it is my voice that speaks, but claiming that the experiences which I had were purely subjective would be confusing interpretivism with solipsism. The intersubjectivity of experience is rendered through observations of social interactions and through my interactions with others captured through the description of situations, behaviours, feelings as well as explicit 'facts' such as delays or spatial arrangements. Second, I use the hybrid of participant and non-participant observation (previously employed by Kociatkiewicz \& Kostera, 2010) as it enables "merging into an impression of the experience" ( $p$. 263). My approach to collecting research stories assumes that our experience of spaces, people and events is narrative-it becomes (to us) "a meaningful succession of sensations and observations" (Kociatkiewicz \& Kostera, 2010, p. 262). Finally, rendering this succession intelligible to readers of this paper entailed compromising the stories' objective realism-they are 'real' but they are also impressionist tales (Van Maanen, 1988), at times startling the complacent viewers and evoking sense of participation (Van Maanen, 1988). These stories are not limited to relaying the facts and true statements; they aim to make the readers feel as though they were actually there with the author (Kociatkiewicz \& Kostera, 2010). In order to create this impressionist landscape of experience (Kociatkiewicz \& Kostera, 1999), I intentionally did not distance myself from the studied field. Thus, the stories are imbued with subjectivity and emotion-immersing in them may not be a pleasant experience.

It is important to note that, although the emotional load and a degree of imposed interpretation - which characterize these personal narratives - are typical vehicles of 'closure', the below texts are intentionally placed within the 'open' context. For instance, the statement that boarding on the Eurostar train is 'disconcerting' is an invitation to experientially relate to both the described background and to the feeling of 'disconcert', thus developing one's own rendition. Therefore, the reader's 'response' to the text is expected (Iser, 1978) and the task of re-arranging and reinterpreting the text is left to him or her. It is an 'open work' in a sense of the author's conscious decision to generate an interactive process between the reader and the text (Eco, 1989). Even though the separate 'cases' or texts may appear 'closed' and uninviting, assembling them in an experiential context of liminality is expected to engender an emotional and semiotic reading (Eco, 1979). If the reader finds some or all of these descriptions 'disquieting' and 'disconcerting' and actively replaces the imposed meanings by his/her own emotions and experiences-it is only for the better: such agency-inducing consequence is inscribed in the area of inquiry.

Admittedly, the method through which understanding of the mismanaged experience is built must be made explicit. This study shall use abduction as a method of not so much arriving at a single valid explanation of the phenomenon, but opening up the grid of existing interpretations to suggest a new conceptualization of a set of instances governed by, it appears, somewhat similar processes.

Abduction refers to a specific logical form of reasoning coupled with a particular intellectual operation-that of arriving at new conclusions regarding the collected data. Such conclusions explore, propose and establish (discover) combinations of features which are new in light of the existing stock of knowledge. Such operation must be clearly distinguished from subsumption of data, which proceeds from an already known rule to explore the particular instance where the rule can be applied, and generalization, which consists in extending combinations of features into a rule. While these two forms of logical reasoning, respectively deduction and induction, are either truth-conveying (deduction) or probable (induction), abduction is more speculative: it proceeds from a known result to an inference regarding the rule on the basis of which this result was achieved and to a subsequent inference regarding the particular case (Peirce, 1931/1958). Something is discovered in the data-a rule, which enlightens the particular instance in which the rule is applied (Danermark, Ekstrom, Jakobsen, \& Karlsson, 1997). Therefore, abduction is a creative process, an intellectual act that brings together things which probably one had never associated with one another (Reichertz, 2010). While abductive inferences may seem risky, they are deeply embedded in social sciences in a number of theoretical accounts. One prominent instance of abduction is provided by grounded theory (Glaser \& Strauss, 1967). While Glaser and Strauss (1967) rarely refer to abduction explicitly, later developments of grounded theory leave no doubts that it is considered important (1987). In grounded theory the process of arriving at a hypothesis is perceived as a "discovery [...], having a hunch or an idea, then converting it into a hypothesis and assessing whether it might provisionally work" (Strauss, 1987, p. 11), creativity is seen as "a vital component of the method" (Strauss \& Corbin, 1990, p. 27) and authors rely on the "flashes of intuition" (ibid., p. 28). All of which are typical and constitutive features of abduction. ${ }^{3}$

While abductive reasoning does not imply scientific infallibility, it is perfectly compatible with qualitative methods (Reichertz, 2010) and, in the interpretivist spirit, may contribute to understanding phenomena through accessing the meanings participants assign to them (Orlikowski \& Baroudi, 1991).

While the goal of interpretivist research is to understand the worlds of others, these worlds are never fully accessible. Even if the voice is given to the respondents or if they are allowed to 'speak' through images (Warren, 2012) when such data are analyzed interpretation is involved-that is:

\footnotetext{
${ }^{3}$ From Umberto Eco's perspective Freud's psychoanalysis, Darwin's theory of evolution and Goffman's theatrical interpretation of social interactions, are also instances of abduction (Eco, 1984).
} 
assumptions regarding the meaning of data are made. These interpretations are often presented as inductively-created types or models to be used for future research and by other qualitative researchers. And yet, whenever the assumption is made that a particular set of rich qualitative data contains some element transferable to another (no matter how similar) research context, such assumption is abductive in spirit: the inference starts with a particular case, leads to a rule (even if limited) and ends up relating to another case-the one to which a rule can (in some way) be applied. Whenever interpetivists attempt to say something about organizations, or their particular type, they affirm the applicability of abduction without applying it explicitly: they assume that their statement can (albeit not in a truth-conveying manner) inform other organizational researchers. When the social scientific accounts (or second level constructs (Schutz, 1963)) are generated by social scientists by means of analyzing the social actors' accounts of their actions (first level constructs), abduction is involved (Blaikie, 2007). For the social explanations to go beyond the specific meanings that people give to their actions a discovery of the insiders' view is needed-abduction is the name given to this process of 'discovering' (Blaikie, 2000). If, for instance, Van Maanen and Schein's (1979) six dimensions of socialization processes can be applied to study different organizations a degree of abduction must be involved. By definition we do not know for certain whether individuals' actions and senses made by them are 'really' made more accessible owing to our study of a very limited aspect of social reality. And yet, we often assume that we have gained some insight which may relate to the wider (e.g. organizational) reality.

The below case studies were collected during the period of 2011-2012 in Belgium and the United Kingdom, and consist in ex-post analysis of and commentary on the multiple observations, brief interactions with organizational actors and the author's contextualized descriptions. In each but one case (museum) the narrative results from the author's recurring (at least four) immersions in the research context. After some deliberation, the author decided to use original names of existing organizations. The reason behind going against the otherwise useful tradition of changing the names to protect research subjects, is that no sensitive factual information is disclosed in the current study (the textual sources used in the study are limited to widely accessible internet and printed sources). In fact, given the experiential framework of this research, it is envisaged that disclosing the real names of studied organizations will enable readers to confront their experiences with the author's observations perhaps facilitating their engagement, critical or otherwise, with the topic of this study. ${ }^{4}$

\footnotetext{
${ }^{4}$ It could be argued that the impact of a specific local context most organizations were of Belgian origin - limits the validity of the study. However, in spite of the relatively high suicide rates (bib0510Eurostat, accessed 12/06/2012) as well as the media's angst regarding the country's uncertain political and administrative status (Le Soir, 'Unity in apathy'; Le Soir, 'Ce pays a-t-il encore un sens?'), Belgium still enjoys a relatively high GDP per capita, even for European standards, and its population seems more prone to actively choose to pay an extra premium for luxury than in most developed countries (Eurostat, accessed 12/06/2012), which complicates arguing a straightforward linkage between macro- and micro-level organizational experience mis-management.
}

\section{Case studies (fieldnotes)}

\section{Eurostar-Halfway through}

The Eurostar train is dubbed to be a relatively easy and comfortable way to travel across the English Channel. Eurostar's business premier tickets for departures from London may cost around $£ 300$ and include, among others: taxi booking service, fast track check-in, luxury waiting lounges, newspapers and magazines on board, as well as meals and drinks served at the seat. Along with the stated mission "changing the way people travel" (Eurostar's homepage; accessed on 20/06/12), deploying luxury brands such as Dolce and Gabbana and Crème de la Mer at the Eurostar London arrivals (JCDecaux, accessed 24/04/14) and advertising the 'longest champagne bar in Europe' on Eurostar's webpage (Eurostar, accessed, 24/04/14) suggests that the company's marketing strategy involves up-market oriented efforts. However, 'the change' does not come without its costs.

First, announcements in three languages: Dutch, English and French, are provided, which means that each of them takes three times longer to complete and - judging from their reactions - seems to disturb some passengers, especially in case of these announcements which relate to today's choice of sandwiches and especially in case of these travellers (including myself) who are leaving before 7 am and intending to take a nap.

The boarding experience appears rather disconcerting as well. There are 10 terminals at Eurostar's disposal on the St Pancras station, some 25-30 trains on any given day. However, it is often the case that two trains depart from London to Paris and Brussels from the adjacent tracks at (nearly) the same time. I watch hundreds of passengers going through security gates and using the same pair of conveyor belts almost simultaneously. Lengthy queues are formed, waiting times extend and frequent delays result. An apparently welloff businessman curses, a group of almost identically-looking bureaucrats chatter nervously glancing at one another and two backpackers seem rather frustrated. While there does not seem to be any particular reason for this arrangement, a clear-cut explanation does exist. The train attendants inform inquisitive passengers, such as myself, that the cost of transit through the tunnel is significantly reduced if time gaps are minimized. Although, as I watch an elderly lady with a sizeable suitcase rushing in havoc out from the Brussels train to the Paris one seconds before the doors are locked, it appears that few passengers appreciate the convenience of this solution.

One morning in early May: the Eurostar train leaves at 7:56 am. At 7:25 there is a queue of approximately four hundred people waiting to go through security. This fact is unusual, since if the train is on time, which seems to be the case, gate typically opens around 90 min prior to departure. At 7:35 it becomes clear that either the train will be late or the crowd immobilized in the waiting area will not manage to catch it. Rumours spread, legs shuffle and curses are heard. The train attendant declares in poor English that due to the delay of an earlier train the 7:56 one is also delayed. I, along with a few other apparently disorientated passengers, realize that it cannot be the case: there was no earlier train on that day's timetable (although there typically is one at $6: 56$ ). 
Responding to immediate passengers' queries the attendant says that the train is late due to today's bank holiday in the UK. It is not true either: the bank holiday took place the day before. Having declared two misstatements, which clearly raised the tension among the waiting passengers-a few of them try to approach the staff member and say something in an infuriated tone of voice - the train attendant vanishes expertly. Then an announcement is heard: "the boarding for the 7:56 train will finish in 10 min". The fact how it can finish if it never commenced is not explained. The following $15 \mathrm{~min}$ or so see a lot of confusing information, a bit of movement towards the gates (someone must have gone through after all) and five or six new queues which form quite spontaneously, but their destination remains less than certain. Some of them merge, some dissolve, while the loudspeaker announces departure of the 7:56 train to London-our train, with our names on the seats. The eurocrats no longer chatter and seem resigned. At that point, another attendant informs that those who were supposed to take the earlier train (the one that never existed) which was held up by the British bank holiday (which ended $8 \mathrm{~h}$ before), had been given our seats and that waiting passengers will be allocated free seats in the next train. The first signs of mutiny are visible, the tension in the air thickens. Passengers are not willing to let the next train (8:52) go, because some of them will no longer have a reason to take the one after that $(10: 56)$, which seems to be an imminent option. In the end, all 7:56 passengers manage to board the 8:52 train, which is also fully packed and arrives at St Pancras over an hour later than planned. Neither throughout the whole journey nor upon its conclusion is any explanation offered. The atmosphere at the arrival station is tense-people rush for the gates, apparently trying to save a few minutes, others seem to make complicated rearrangements over the phone, and yet others still try to get their message through to the member of staff. None of this appears to be successful-it is far too laud and the crowd densely fills in the whole platform.

\section{Mediamarkt}

Located at the top floor of a large business enterprise in Brussels city centre this multi-brand store selling different household appliances is the only option of this kind of shopping for clients looking for a moderate price range. The shop occupies the whole floor and only one set of escalators leads to it, as well as descends. Apart from posing a threat in the event of emergency, it is both uncomfortable during more crowded shopping periods and confusing due to the exit and entrance being located at the opposite sides of the hall. I observe groups of people trying to descend, finding out that they picked the ascending escalator, turning back and becoming blocked by the others who made the same mistake. Another interesting feature of this venue is the luggage storing system. One cannot, in any case, enter Mediamarkt with any kind of bag or backpack. It is obligatory to use the lockers located in the hall, which operate according to a rather peculiar rule: a self-created four-digit code needs to be used to lock them and no key is given which means that the locker's number must be duly remembered. If the latter is forgotten or lost, chances of getting one's things back (which may include car keys or cell phone for instance) become slim: there are over four hundred lockers and although they are theoretically transparent very little can be seen through frosted plastic. A middle-aged man spends a few minutes looking for his locker-no staff member in sight. He finds it, to his apparent relief.

I observe the abundance of shop clerks randomly distributed in the store. Quite often a gang of them huddles together around e.g. washing machines, while the TV department is devoid of any assistance even if the density of clients would suggest that the opposite would be more effective. Some of them roam without an apparent agenda through deserted alleys, while I spend almost an hour waiting for help. Meanwhile, a young man wanders through the store with a bunch of cables in his hand asking every available clerk a question which apparently remains unanswered as his ramble continues. When help arrives it is of little use to me: I did not manage to find what I was looking for or have my question answered; perhaps because the majority of staff consists of trainees whose experience rarely exceeds 1 month. Whenever I managed to buy a functioning appliance, not lose my backpack and find my way out I considered myself lucky.

\section{The Nespresso experience}

The basic idea behind the main Nespresso store on Avenue Louise in Brussels simple: one goes there to buy coffee capsules for one's own coffee machine. But make no mistake, it is a veritable rite of passage-you'll have to go through a lot to enjoy your morning espresso. I had forsaken all hopes for a relaxing experience when upon making the first step inside the shop assistant from behind the counter asked me, in a polite but demanding manner, what is it that I wanted. True, it is possible to buy something else than coffee here, since coffee machines and expensive sugar sachets are also available, but the number of clients acquiring these items is miniscule and even then coffee is usually brought on board anyway. Why then is shop personnel trained to pose such a question to every single client remains a mystery. The most commonsensical response ("I would like to buy coffee") prompts the attendant to push some buttons on the console in front of him and provide me with a piece of paper with my queue number on it. It makes me wonder: Why the client could not do it him/herself, if this elaborated post officeinspired layout concept is deemed relevant in the first place? It is, however, merely the beginning. The waiting area is upstairs, despite a large and apparently unused space available on the street level. The selling stands are located on both sides of a rather thin corridor in which four chairs are placed to the convenience of the waiting customers. The latter are usually between 20 and 40 in number and during peak-hours something more like 60 . Within the waiting area one can either, literally, stumble upon glass prisms filled with coffee or watch a Nespresso commercial - the one with George Clooney and John Malkovich - on a rather small screen located in the corner. Curiously enough, the same screen is also the only space where the digit indicating the number of currently attended client is displayed, which makes all customers crammed in a tiny area unwittingly and repetitiously watch Clooney buying coffee in another, apparently more comfortable, Nespresso establishment. Incidentally, the screen is not visible from the small lobby, in which previously the mentioned chairs are located. The 
layout owing to which the customers are tightly compressed between two rows of selling stands and thus constantly shifted, poked and pushed by the lucky ones whose number came up, further contributes to the customers' apparent lack of comfort: people sit or stand uneasily trying to peak over one another's shoulder to find out if their number came up. Since out of twelve stands, not more than three or four are usually serviced at a time, the waiting time typically amounts to 30 or $40 \mathrm{~min}$. When the time comes the attendant is extremely meticulous, very polite and intensely unnatural in whatever he or she happens to be doing. As a result, the process which might have taken 2 min at most (take 20 or 30 slim and light boxes from the shelf behind and put them in a bag) takes over $5 \mathrm{~min}$, which, judging by their facial expression and apparent uneasiness, adds to the evident agitation of other clients.

\section{Post office in Brussels}

I want to send a letter but have forgotten to arrange for an envelope. There are three solutions which seem to remain available to me. The first one is to buy envelopes wholesalethey usually come in packages containing hundred pieces. I do not want to spend at least 10 euro to get one envelope, so I ponder the second option-to try to find a free specimen, which I know is sometimes made available by post clerk, but this time I am disappointed. Buying one envelope is not an option.

I have finally managed to acquire an envelope and put a letter in it, but I still need to write the address. However, a pen is not available to customers at the post office. Sometimes it is possible to buy one there, but again, obstacles accumulate. The stationary stand is usually attended by someone who is not there at the moment. It being anything between 5 and 30 min prevents me from getting my client number, because chances are that I would not be ready with my letter when my turn comes. I observe an elderly lady's agitation as she attempts to write down the address (with her newly acquired pen) before her number comes up; she fails and to the apparent dislike of the waiting customers she tries to finish in a haste while being attended to by the clerk.

Despite the fact that arriving at the post office with a letter slit in an envelope on which the recipient's address is written is highly advisable, it does not protect me from further inconveniences. Most post office employees do not speak English or any other foreign language (and rarely Dutch or German despite these being official languages in Belgium) and their rapid French is filtered through a double glass separating me from them. My comprehension of what was said is only exceptionally assisted by an external loudspeaker.

Sometimes, the post office clerk accidentally calls my number while $s /$ he is still occupied, which makes me wait and inanely watch other customers, with numbers which follow mine, being serviced. S/he often speaks inaudibly making me guess the price of the service or the date of delivery. I witness a frustrated customer, possibly of Hispanic origin, desperately trying to communicate something to the clerk in his relatively fluent, but far from perfect French. He clearly struggles to hear what the clerk is saying. I leave before communication is established between them.

\section{Exki-Healthy food}

Inconveniences start the moment I enter. I open the door and immediately have to watch out not to hit the person standing to my left (where a pile of trays is located and there is always a crowd of customers trying to get one) or to my right (where the soup stand is). If I were patient enough to wait in the tray line and the soup line, I go to the food stand. There are always plenty of customers standing there in a much disorganized way, due to an equally disorganized manner in which food is displayed, making it almost impossible not only to buy something but also to even see what actually there is on the shelves. There will always be a staff member to add to the crowd-currently putting something on the shelves, taking something out or just wiping the counter. Sometimes, they unexpectedly shout "bonjour!" into my ear while I am choosing my food. Especially multilingual staff is likely to shout to clients in three languages-first French, then Dutch and English, making me even more disoriented as to how (if at all) I should respond. The disorientation is shared by other clients, it seems, as they make multiple attempts to reach for their food and then awkwardly manoeuvre around the hyperactive employees.

In the middle of the whole venue there is a huge pillar. I have to watch out not to bump into the person coming from behind it with their tray, as I would not be able to see them before.

After having already spent 15 min trying to pass the other customers, having stood in the tray line, the soup line and the food line, I have another line to go-the tills. This one is actually the most challenging; there are usually four cashiers, two on each side of the central pillar. However, there is one line to each of the two pairs of cashiers. When I try to form another one to make things faster, so that there's one line per one cashier, the staff looks at me reproachfully. My feeling of guilt intensifies as I glance around-the way other customers look at me suggests that I have done something wrong. When I finally arrive at the cashier's desk, usually after having spent at least $10 \mathrm{~min}$ in the line, the cashier will ask me numerous questions-would I like it to eat in or take away, would I like plastic cutlery or not, would I like something to drink with my food, would I like some ice with my drink, etc. But the final question is yet to come, would I like "un café pour après?". If I do agree to have a 'coffee for later', I will get it printed out on my receipt and I will have to pick it up at the counter after l've finished my meal. A seemingly good solution - I do not have to stand in line twice - creates further problems. I observe at least three customers who cannot make sense of the question askedthey inquire, still do not seem to understand, slow down the queue and finally concede with a 'Oui'. When I arrive at the counter to pick up my coffee, there's a line of people looking at me with animosity when I try to cut in the line (and consequently slow down the sales process for the rest of the people in it). I can also choose (as some people who seem to be more sensitive to hostile looks do) to come up to the counter on the side and hand in my ticket to the cashier directly. In that case I have to wait right by the kitchen, creating a further obstacle for the staff or people trying to pass through with their trays. Having to decide between being hated, being an obstacle and not having a coffee (for which I have already paid) I choose the last option. 
On my way to the exit I must be careful to pass around the soup line and the tray line, and I am given a farewell by another hyperactive staff member shouting "au revoir". I reply "au revoir" with a sigh of relief and recover from the whole experience for the rest of the day.

\section{The museum}

Rene Magritte's house-turned-museum in the Jette district is one of Brussels' tourist attractions and hosts a number of original items later reproduced in Magritte's paintings. Upon my arrival the curator offers 2 options of visiting the house, none of which seems to include the possibility of "just visiting' it. One can start it right away and then be interrupted in order to participate in the curator's talk on 'food in Magritte's paintings'-it does not seem to be optional. I can also start my visit in the adjacent house where another contemporary painter has her exhibition and then be transferred to the proper place. I have no intention of spending the afternoon watching a different exhibition than planned, and the curator's remark that she finds the other exhibition 'weird' does not reassure me, so I choose the first option. The museum is tiny, which may actually add to the charm, but the curator's office is strategically placed on the mid-level. As a result one's attempts to enjoy Magritte's creations are constantly scrutinized, and even if hidden away, the visitor is surrounded by typical office noise-chatter and phones ringing. Whether or not one wishes it, the curator often contributes to the visitor's experience with her inside-out knowledge of the topic. I see a young couple - they look genuinely interested in the exhibition and try to enjoy it expertly trying to avoid the curator's gaze. To no avail, they are soon approached and seem unhappy as the curator explains some intimate detail of one of the paintings.

As previously assumed, 'the food talk' is practically mandatory; all newcomers must go through it in order to be admitted. I witness the arrival of a middle-aged couple, apparently not interested in 'the food'-they grudgingly join the tour. So do I, when prompted if "I've finished the visit upstairs" (which I did). The talk is not engaging, but it is rather long, and I would rather have it done over with. Very clearly, it would have been the wish of the two newcomers as well. It does not seem to be an option either. When it eventually ends it leaves me, and other visitors apparently, exhausted.

\section{Analysis}

The following discussion scrutinizes various experiential agency-inducing aspects of the above case studies. As indicated before, abductive reasoning facilitates forming new associations and arriving at constructivist interpretation of the studied phenomena. Inasmuch as inferences are made to 'the rules' and later instances in which these are applied, the abductive method is used. The collated data are analyzed with a view to identify instances in which the affinities between experience-producing processes are present and in which likeness between mis-managed customer experiences exists. In other words, the aim is to identify different aspects of the 'subjective' experience mis-management.
Eurostar's attempts at managing customer's experience are rather explicit: separate queues for 'premier' passengers, smart staff uniforms projecting a professional image, elegant décor of premium carriages, and multilingual (typically, friendly and relaxed) crew. Hence, the design of Eurostar's service to some extent encompasses sanitizing efforts (Johansson \& Näslund, 2009) at all levels: physical (spaces), emotional (attitudes) and personal (customer management). However, all positive experience-producing effects of these efforts may (and do) fall short of achieving their purpose in many respects. First, due to the illogical design of service, vide two simultaneous departures from the same platform or flawed departure schedules. Second, because of deficient execution of service: misinforming passengers and depriving them of their seats, as if it were a standard procedure. Finally, the customer's experience is rendered unpleasant on account of the overkill of service, e.g. irritating (in terms of number, duration and triviality) announcements during the journey.

In Mediamarkt the source of dissatisfaction is, again, inherent in the customer's experience mis-managed at least in two respects: it is poorly designed and irritatingly executed. As regards the former, the storage/locker system comes extremely (un)handy. Regarding the latter, staff attitudes make shopping a memorable, if unpleasant, event. This effect appears despite ostensible efforts to achieve the opposite-as the impressive amount and technological sophistication of the new lockers, as well as the large number of employed attendants would imply.

The Nespresso store's physical layout, doubtful design of service and its irritating intensity, make for the truly unpleasant experience one encounters. If enforcing interaction with the customer on the outset was supposed to create an opportunity for welcoming him/her in the 'realm of Nespresso' it is certainly a wasted one. The physical space appears maladjusted to both the number of customers served and the way they are attended, which coupled with the questionable entertainment offer augments the feeling of awkwardness which most clients experience and results in their dissatisfaction.

One can safely infer that in case of the post office all attempts at staging customer experience fail in every possible respect. Props (pen, envelope) are flawed or non-existent, actors (staff) are poorly trained and unconvincing, and the script, if there is one, appears to be from a different play-the one in which the service-taker does all the work.

While intentions behind creating Exki seem self-evident to provide a relaxing, environmentally conscious and healthy lunch option - the experience is rendered intensely unpleasant due to the inconvenient physical layout, staff attitude (enforced interaction, hyperactivity) and dubious solutions to serving customers (such as 'a coffee for later'). As a result, a puzzling experience is created: Is it a fast-food or a slowfood? Is it self-service based or not? Am I standing in a queue or not? Disambiguating the context demands a degree of concentration and involvement which customer has no reason to expect in most establishments. Struggle and resignation seem to be the only options.

The experiential letdown of the Magritte's house experience is particularly acute. The experience's goal as well as the basic rationale behind the functioning of the whole establishment seemed relatively well-defined-an aesthetic 
pleasure of the visitor. However, this single promise remained unfulfilled due to multiple interruptions in the flow of experience. The obstacles, which created a boundary between the viewer and the artwork, appeared on the level of the visitorcurator interaction (for instance in the form of 'supplementary attractions'), as well as due to the arrangement of space. Both contributed to the uneasiness of experience which precluded deriving any pleasure from it.

\section{Three facets of experience mismanagement}

In the current research (similarly to Strauss's explication of grounded theory method [1986]), I make the implicit abduction explicit-other people's experiences (cases) are perceived as informed by the 'facets' (or rules) which I arrived at by analyzing particular cases of experience mismanagement derived from self-reflective inquiry. This study does not claim that 'it really is so', it merely emphasizes that gathered data make the threefold characteristic of experience mismanagement and the situational liminality hypothesis a handy sensemaking device as well as a likely formula to analyze future experiential data in a critical frame.

I would like to posit that the above results of a selfreflective inquiry justify abducting the customer's experiential dissatisfaction from the three facets of experience mismanagement-as they are experienced by the recipient:

- Deficiency of logic - the illogical and unintuitive design of experience

- Flaws in delivery-poorly executed flow of customer experience

- Overkill of experience-the accumulated imperfections of the experience staging process ('shadow').

As this study will attempt to demonstrate such obstacles to effective creation of experience result in situational liminality, involving both organizational spaces and actors. The disambiguation of liminality, if attempted, demands a significant emotional and, sometimes, physical effort potentially leading to dejection and fatigue.

The experiential framework of inquiry does not enable for reifying the 'mismanagement' from the provider's perspective-no inference that e.g. particular spatial design will necessarily result in the experience of liminality can be made. Only subjective experience and observed intersubjectivity subsumed to experiential framework by means of abduction (which enables going from e.g. "they seem uneasy" to "they experience uneasiness") can be analyzed. However, taking interpretivism rather than solipsism into account, one is compelled to admit that the experiences in question appeared in particular organizational contexts. Hence, while admittedly the situational liminality is a psychological phenomenon, one must not abstract from its material context: people, spaces and actions accompanying experienced liminality. Inquiring into the way in which materiality affects subjectivity would be a reversal of an old constructivist question (How does subjectivity [complicated human psychology] result in something objective [e.g. institutional order] Berger \& Luckman, 1966). However, this study will instead focus on a different interpretivist notion: How can the subjective elements of a particular experience (that of situational liminality) be categorized using the contextually relevant vocabulary. In other words, how can situational liminality be approached taking into account the individual's experience of organization?

\section{Deficiency of logic}

In many respects the customer's expectations as regards the rules according to which 'things are done' are betrayed by structural issues with the service's design. Lockers devoid of portable keys and requiring a four-digit code compel the customer to memorize the sequence of six or seven digits (or write it down)-an unusual request if you just need to buy a light bulb. When travelling on a high-speed luxury train, one will not reasonably expect to be deprived of a reserved seat, or to swarm with hundreds of other passengers, especially if most platforms are free. Designing the flow of customers in the most awkward manner possible by a fast food chain, slowing down the process by asking each coffee-craving customer a non-sensical question in a coffee shop and taking the formula of an open working space for designing a museum seem to belong to the same category.

Naturally, none of this suggests that interweaving a surprising element with other elements of service delivery is inherently a bad thing. That, however, is the crux of the matter: in the case of e.g. theme parks or adventure holidays, a surprise is (paradoxically) an expected element; it belongs to the logic of the experience. The above solutions do not belong to it-they are as 'surprising' as a disease can be.

\section{Flaws in delivery}

The awkward aspects of experience derived from the execution of service rather than its design, include: the brazen treatment of customers (misinformation regarding the reasons of train delay), complete lack of client's attendance (despite a wealth of staff standing around), pushing customer's lack of comfort to the extreme by forcing him/her to repetitiously participate in the same performance (watch the same commercial), randomly distributing merchandise (food items), and multiplying trivial obstacles which preclude the customer's satisfaction (derived from an aesthetic experience).

While, ostensibly, flaws in delivery may be easier to eliminate than illogical elements of design, they tend to resist change quite effectively - in all but one case observations were multiple and spread over time, but no changes in the way experience was created were noted. Hence, interestingly, these petty but irritating physical or behavioural artefacts seem to ossify easily, potentially, perhaps, becoming the elements of design.

\section{The overkill of experience}

Kociatkiewicz and Kostera, (2012, p. 482) distinguish between fast and slow facet of experience economy events: the subjective dialectic "between catching the moment and reflecting upon its context". They also demonstrate how staged and managed experience economy events (created in [or through] nostalgia fairs, shopping malls, airports, etc.) may produce 'a shadow side' (2010). A shadow, the Jungian unwanted, rejected and destructive element (Jung, 1951) appears due to imperfect, somehow ineffective, staging process, which upon the authors' reflection occurs to 
produce side effects, "the feelings that, by not being acknowledged in the official staging process, become independent of the managed identity and accumulate at the margins, forming the shadow" (Kociatkiewicz \& Kostera, 2010, p. 258). While the authors consider the possibilities for reintegration of 'the shadow' into the operation of experience economy organization (ibid.), here the failed, shadow-generating, organizational attempts to impose the notions of functionality, effectiveness and comfort will be explored.

I would like to posit that shadow accumulates due to the overflow and overkill of subjectively experienced interaction which is difficult to slow down and reflect upon. The trivial and repetitive announcements on the train, disorienting intensity of welcome staff's behaviour in Nespresso, enforced multiple interactions with attendants in Exki and an overwhelming hyperactivity of the curator (as well as of all the above, to some extent) create an excess of fleeting, momentary experience from the customer's viewpoint. Excess and kitsch may naturally be sought after and become an indispensable part of experience and means of artistic expression (sculptures created by Jeff Koons and John Waters's movies are the examples). In such cases, however, excess is expected to be present and its consumer is prepared to deal with it, for instance by patient reflection which can capture the hues of the described situation (Kociatkiewicz \& Kostera, 2012). The perceived mis-management of experience by overkill is perhaps the most damaging to the relationship with the consumer of all three facets of mis-management, and potentially the most difficult to eradicate by the provider if capitalist logic of accumulation (Heilbroner, 1985) is taken into account. However, as it seems, 'the more the better' is far from being the universal recipe for managing the experience. The shadow which accumulates because the experience was totalized, over-managed, and forcibly imposed may result in its complete rejection. The staging process characterized by overkill may therefore be self-destructive and thus ineffective.

\section{Discussion-Situational liminality}

As this study will further attempt to show, the sensed mismanagement of experience on these three accounts results in the potentially comfortless position of ambiguity, which shall be referred to as situational liminality. Thus, it is inferred abduced - that the above instances are sufficient for such liminality to appear.

Anticlimactic design of experience may provoke questioning its framework. For instance, trivial shopping may become, to some extent, a complicated memory-and-orientation task, a luxury travel an arduous effort, and a fast-food quick bite turns into a time-consuming meal one would expect in a 'slow-food' establishment. 'To some extent', but not entirely, since the framework is questioned, but not overturned. Similarly, the faulty delivery of experience may occasion that either one's definition of a situation (for instance, autonomously drawing aesthetic pleasure from an artwork) or social status (e.g. respectable businessman on a business travel) starts to verge upon their profound reformulations (a guided visit in a high security facility and student trip on a shoestring budget, respectively). While not radical enough to redefine the situation thoroughly, these misgivings create a tension between the original standpoint and other emerging options. The shadow-inducing overkill of experience alike results in partially invalidating the established context of interaction. Too much of customer assistance compromises the notion of self-service, same as does the overflow and speed of communication to the sense of luxury. Once the boundary between diminishing the returns derived from the experience and accumulating the shadow is crossed, the resulting excess starts to bridge different conceptualizations rendering one's bearings more difficult to get.

Hence, the situational liminality ${ }^{5}$ expels the subjects of experience from their safety zone and forces them to confront multiple choices generated by the ambiguity in which they are immersed. The liminal, whether temporal, spatial, notional or situational - the last one, I would claim, encompassing the previous three - is the nowhere land, which unfolds between the separate markers provided by one's constructions of social reality. Transient and unstable as they may be (Berger \& Luckman, 1966), they nevertheless become relatively more constant if the patterns of social interaction habitualize and institutionalize (ibid.) into established contexts, such as, ostensibly well-defined, commercial exchanges between consumer and organization. However, if the point of gravity of such interaction shifts away from delivering an object or a service and moves towards dealing with the experience, the context becomes relatively more prone to be destabilized if the experience is deemed mismanaged.

As indicated in Table 1 below, the threefold subjective mismanagement of experience contributes to the partial uprooting of the original context and leaving the experiencing subject in the near void, 'betwixt and between' (top vertical arrow). The negative aspect of the situational liminality consists in ambiguity which the subject is compelled to overcome. Naturally, it is always 'somebody's' experience, that is, it remains on the side of the recipient, but it nevertheless is an experience of something: of an aspect of surrounding reality formed at least partly by the described organizational context (otherwise, how would experience economy be even possible?). If people act as if they were confused, felt awkward and uneasy, and these impressions perfectly correspond with the self-reflective data the ambiguity imposes itself on the analytic agenda. Naturally, ambiguity in itself is not an adverse notion. Likewise ambiguous situations may (e.g. Boss \& Greenberg, 1984; Buehler \& Pasley, 2000), but do not have to be construed as negative (Sutton-Smith, 1997; Bateson, 1955/1973; Spariosu, 1997; Empson, 1955). Thus, the drive to disambiguate the liminality is not inherent in the negative connotation, but in the contextual demand-the liminal situation created by the mismanaged experience appears psychologically uncomfortable. A person subjected to such experience may strive to arrive at a more clear-cut definition also for practical reasons, most typically: "Will I ever again choose this service or not?"

\footnotetext{
${ }^{5}$ The term 'situational liminality' was previously used in anthropological context to account for the mortuary rites practiced by certain tribes (Helms, 1998), but according to the author's knowledge it has yet to be employed in the context of organization studies.
} 
Table 1 The framework of mis-managed experience.

Table 1. The framework of mis-managed experience

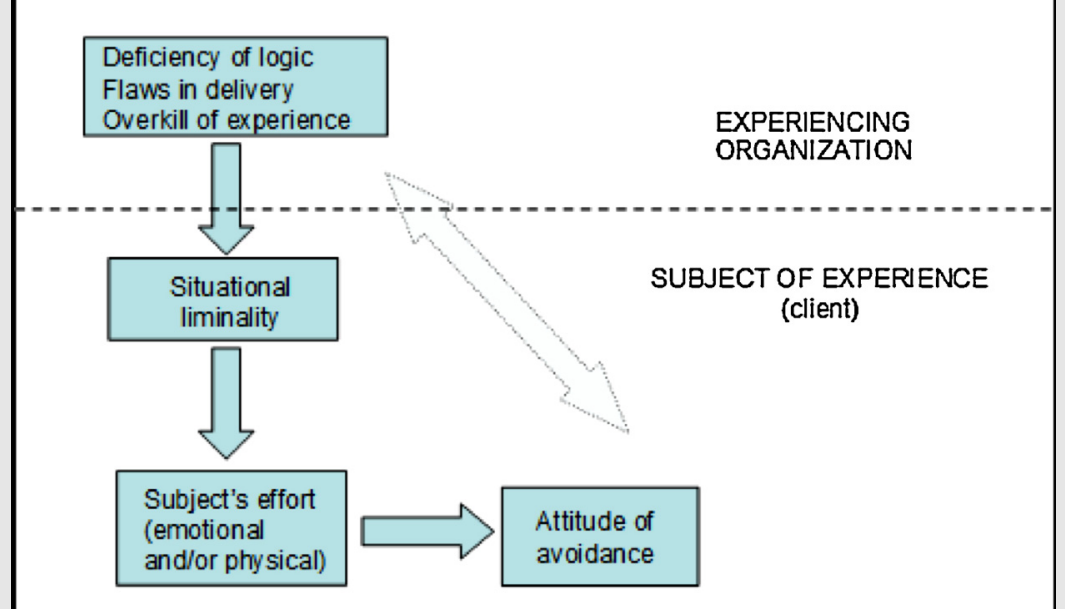

Source: Author's own elaboration

However, as the lower vertical arrow in Table 1 suggests, to disambiguate means to make an effort. Using the previously discussed example, participating in the Exki experience is a challenge. To simplify: one must choose either a fast-food or slow-food reality or try and negotiate between these constructions. Each choice inevitably leads to further multiple choices which involve numerous actions. For instance, the fast-food option entails jostling through the inert crowd gathered around the food stands, creating your own queue leading to the tills, actively avoiding the physical obstacles (the pillar, soup pots scattered around) and so on. The behavioural aspect is obviously preceded by a number of mental processes, i.e. resolutions, decisions to undertake actions, as well as accompanied by others, e.g. ignoring the multilingual greetings, disregarding the superfluous questions posed by the staff, etc. On the other hand, the incentives to indulge oneself in the slow-food experience (a vast selection of organic food, do-it-yourself food options, large seating area, etc.) are present and render abiding by the fastfood framework difficult. Whichever rendition of the situation is selected, this entire series of actions, most of which would not be required under the conditions of a more unequivocal definition (e.g. McDonald's), demand constant activity and alertness on the part of the experiencing subject. Disambiguating the liminal situation consists in laborious defying and deconstructing the mis-managed experience-a toil which must be undertaken by its beneficiary: a client, a customer, a visitor. It seems natural to assume that, except circumstances in which a strong socially-predefined framework is imposed (e.g. a researcher in the field, a masochist, etc.), s/he will strive to minimize the emotional and physical exertion required, as a result avoiding the exposure to such experiences in the first place (the horizontal arrow in Table 1). Naturally, there is a possibility that this negative feedback will impact the experiential setting-organization will enable the client's experience to inform its operations aligning them to the customer's perception, which may reciprocally influence the client's future attitude in line with the interactivist theory of emotion. ${ }^{1}$ However, undoubtedly, such potentiality (represented by the transverse two-sided arrow) may be mitigated by the embeddedness of preexisting non-malleable (and misaligned with the existing socially-affected psychological response patterns) aspects of organizational design. Thus, being exposed to experience subjectively received as mis-management through deficient logic of its design, flawed delivery and overkill, may result in the intersubjectively perceived liminal situation, the disambiguation of which demands a high enough level of mental (and often physical) effort to occasion the attitude of avoidance on the part of the experiencing subject.

The above assertion can be deemed an abductive hypothesis. As Guest et al. (2012) explain, exploratory qualitative analysis commonly generates hypotheses for further study. In a similar vein, this 'hypothesis' is not a testable hypothesis of a quantitative study, it is merely a research-induced observation: an invitation to conduct further research, not a discouragement to undertake it since 'the problem is solved'. It has not been solved, it is doubtful whether it can ever be, but noticing it may, hopefully, facilitate further reflections on the subject.

\section{Conclusion}

If, as Zygmunt Bauman suggests, uprootedness, disembeddedness and betwixt and between-ness are the hallmarks of our times, then, possibly the liquidification thesis grants some rationale for the experiential framework discussed in this paper. Provided that the stable footing for social interactions increasingly dissolves, why would experience economy be expected to become an antidote? If Eurostar's trade 
is relocation, if Brussels European quarter's post offices and Exki's way is to cater to expatriates and Mediamarkt-look-alikes famously offer an overabundance of choice to disorientated consumers (as Ritzer, Gabriel and Bauman convincingly claimed, each in his own manner), then situational liminality may be the logical extension of liquid modernity. One's experience as the customer in the liquid era appears to be just as uprooted as one's experience of the social realm: both lack the (subjectively perceived) stable markers and predictable organizing rule. As members of 'the social' we co-produce (liquidify) its institutions and we experience emerging (liquid) organizations.

It is important to note that the situational liminality may suitably describe the experiential framework of eponymous critical subject: an individual entangled in the grander discourse of structurally-imposed prohibitions and sociallyenforced behaviours, vaguely conscious of their existence and thus marginally reflexive. Being forced into the liminal situation puts one on the verge of transforming such latent criticality into an embodied critique evinced through e.g. open disagreement (quarrel), tacit discord (frowning), active seeking for alternatives (e.g. forming new queues), or rejection (boycott). The agency-inducing side of such experience is not negligible from the critical perspective, as it may enable to diversify critical inquiries into experience economy events (currently) typically pursuing their agency-limiting aspects. There is more to the shadow than its disempowering burden.

Apprehending the resulting ambiguity of the subject's position through the lenses of situational liminality, should also be perceived as an attempt to endow the experience economy with a suitable conceptual input (1), and to contribute to the constructivist understanding of commercial interactions within the experiential framework (2). It seems plausible that exploring the spaces and objects construed by the experiencing subjects as 'neither here nor there' could potentially generate some momentum for organizational research in the area of experience economy. In particular, the situational (agency-inducing) 'critical' moments of experience economy events could be further explored to reflect on the broadly understood 'effects' of failed staging of experience at organizational and individual level. The ingraining of liquidity, and thus ambiguity, within the logic of current social, cultural and economic exchanges, emphasizes the importance of experiential frameworks explicitly (or implicitly) designed to provide the subject with the counterbalancing experiences evoking embeddedness, tradition or continuity. Indeed, such 'return-to-the-roots' experiences are currently widely offered through an overwhelming range of experience economy events in historical (e.g. 'heritage industry'), geographic (e.g. agro-tourism); sartorial (vintage clothes), culinary (return to basic, 'forgotten' food items), spiritual/religious and wider cultural (New Age) frameworks. This abundance of attempts at 'staging' some sort of social embeddedness provides ample opportunities for critically reflecting on their misgivings (e.g. aesthetic or behavioural) paradoxically resulting in even more ambiguous and awkward experiences. The concept of situational liminality proposed in this paper, may provide a fitting conceptual background within the realm of experience economy for venturing into these relatively uncharted terrains (with notable exceptions including Kociatkiewicz \& Kostera, 2010, 2012).

The use of 'may' in the hypothesis advocated above, renders it untestable in the sense of a strict scientific inquiry, but such is in any case not expected from the potential addressees of this study. If instead of being rigorously tested, the abductive hypothesis will help to inform researchers' non-functionalist efforts generating new qualitative findings in the field of experience economy and beyond, the aims of this study will be fulfilled.

\section{References}

Barney, J. B. (1986). Organizational culture: Can it be a source of sustained competitive advantage? Academy of Management Review, 11(3), 656-665.

Barney, J. (1991). Firm resources and sustained competitive advantage. Journal of Management, 17(1), 99-120.

Bateson, G. (1955/1973). A theory of play and fantasy. In G. Bateson (Ed.), Steps to an ecology of mind (pp. 177-193). New York, NY: Chandler.

Baudrillard, J. (1970/1998). The consumer society. Myths and structures. London: Sage.

Bauman, Z. (2000). Liquid modernity. Cambridge: Polity Press.

Bauman, Z. (2001). The individualized society. Cambridge: Polity Press.

Beech, N. (2011). Liminality and the practices of identity reconstruction. Human Relations, 64(2), 285-330.

Berger, P., \& Luckman, T. (1966). The social construction of reality: A treatise in the sociology of knowledge. Garden City, NY: Doubleday.

Blaikie, N. (2000). Designing social research: The logic of anticipation. Cambridge: Polity.

Blaikie, N. (2007). Approaches to social enquiry. Cambridge: Polity.

Boje, D. M. (2001). Narrative methods for organizational and communication research. London: Sage.

Boss, P., \& Greenberg, J. (1984). Family boundary ambiguity: A new variable in family stress theory. Family Process, 23, 535-546.

Buehler, Ch. , \& Pasley, K. (2000). Family boundary ambiguity, marital status, and child adjustment. Journal of Early Adolescence, 20(3), 281-308.

Clarke, S. (2006). Theory and practice: Psychoanalytic sociology as psycho-social studies. Sociology, 40(6), 1153-1169.

Clegg, S. R., Kornberger, M., \& Rhodes, C. (2004). Noise, parasites and translation: Theory and practice in management consulting. Management Learning, 35(1), 31-44.

Cunha, M. P., \& Cabral-Cardoso, C. (2006). Shades of gray: A liminal interpretation of organizational legality-illegality. International Public Management Journal, 9(3), 209-225.

Czarniawska, B. (1997). Narrating the organization: Dramas of institutional identity. Chicago-London: University of Chicago Press.

Czarniawska, B., \& Mazza, C. (2003). Consulting as liminal space. Human Relations, 56(3), 267-290.

Danermark, B., Ekstrom, M., Jakobsen, L., \& Karlsson, J. (1997). Explaining society: Critical realism in the social sciences. London: Routledge.

Debord, G. (1967/1995). The Society of the Spectacle. New York, NY: Zone Books.

Duffy, E. (1941). The conceptual categories of psychology: A suggestion for revision. Psychological Review, 48: 177-203.

Eco, U. (1979). The role of the reader: Explorations in the semiotics of texts. Bloomington: Indiana University Press.

Eco, U. (1984). Semiotics and the philosophy of language. Bloomington: Indiana University Press.

Eco, U. (1989). The open work. Cambridge: Harvard University Press. 
Eisner, E. W. (1991). The enlightened eye: Qualitative inquiry and the enhancement of educational practice. New York, NY: Macmillan Publishing Company.

Empson, W. (1955). Seven types of ambiguity. New York, NY: Penguin.

Eurostar: main page.(www.eurostar.com/UK/uk/leisure/about_eurostar.jsp, accessed on 20/06/12).

Eurostar: travel information.(http://www.eurostar.com/uk-en/ travel-information/at-ourstations/london-st-pancras-international\#.U1 kil1VdWsw, accessed on 24/04/14).

Eurostat, =Cause of death statistics'.(http://epp.eurostat.ec.europa.eu/statistics_explained/index.php/Causes_of_death_statistics; =GDP per capita in PPS'http://epp.eurostat.ec.europa. $\mathrm{eu} / \mathrm{tgm} /$ table. do?tab=table\&init=1\&plugin=1\&language=en\&pcode=tec00114, both accessed 12/06/12).

Fineman, S. (1996/1999). Emotion and organizing. In C. Hardy (Ed.), Studying organization. Theory and method (pp. 289-310). London: Sage.

Fournier, S., Dobscha, S., \& Mick, D. G. (1998). Preventing the premature death of relationship marketing. Harvard Business Review, 1: 42-51.

Gabriel, Y. (2000). Storytelling in organizations: Facts, fictions, and fantasies. Oxford: Oxford University Press.

Garsten, C. (1999). Betwixt and between: Temporary employees as liminal subjects in flexible organizations. Organization Studies, 20, 601-617.

van Gennep, A. (1909/2004). Rites of passage. London: Routledge.

Gentile, Ch. , Spiller, N., \& Noci, G. (2007). How to sustain the customer experience: An overview of experience components that co-create value with the customer. European Management Journal, 25(5), 395-410.

Geertz, C. (1973). The interpretation of cultures: Selected essays. New York, NY: Basic Books.

Glaser, B. G., \& Strauss, A. L. (1967). The discovery of grounded theory: Strategies for qualitative research. New York, NY: Aldine de Gruyter.

Golafshani, N. (2003). Understanding reliability and validity in qualitative research. The Qualitative Report, 8(4), 597-607.

Guest, G., MacQueen, K., \& Namey, E. (2012). Applied Thematic Analysis. Thousand Oaks, CA: Sage.

Guimarães-Costa, N., \& Cunha, M. P. (2009). Foreign locals: A liminal perspective of international managers. Organizational Dynamics, 38(2), 158-166.

Hawes, J. M., Mast, K. E., \& Swan, J. E. (1989). Trust earning perceptions of sellers and buyers. Journal of Personal Selling \& Sales Management, 9: 1-8.

Heilbroner, R. L. (1985). The nature and logic of capitalism. New York, NY: Norton.

Helms, M. W. (1998). Access to origins. Affines, ancestors and aristocrats. Austin: Texas University Press.

Hochschild, A. (1983). The managed heart: Commercialization of human feeling. Berkeley: University of California Press.

Hochschild, A. (1997). The time bind: When work becomes home and home becomes work. New York, NY: Metropolitan Books.

Iser, W. (1978). The act of reading. A theory of aesthetic response. London and Henley: Routledge and Kegan Paul.

JCDecaux. (2014). JCDecaux /http://www.jcdecaux.co.uk/airport/ eurostar-arrivals-ideal-environment-luxury-brands $\rangle$ (accessed on 24/04/14).

Johansson, M., \& Näslund, L. (2009). Welcome to paradise. Customer experience design and emotional labour on a cruise ship. International Journal of Work, Organisation and Emotion, 3(1), 40-55.

Johnson, D., \& Grayson, K. (2005). Cognitive and affective trust in service relationships. Journal of Business Research, 58: 500-507.

Jung, C. G. (1951). Aion: Researches into the phenomenology of the self. (Collected works. Vol. 9 Part 2). Princeton, NJ: Bollingen.

Kivlighan, D. M., Lo Coco, G., \& Gullo, S. (2012). Attachment anxiety and avoidance and perceptions of group climate: An actor-partner interdependence analysis. Journal of Counselling Psychology, 59(4), 518-527.

Kociatkiewicz, J., \& Kostera, M. (1999). The anthropology of empty spaces. Qualitative Sociology, 22(1), 37-50.

Kociatkiewicz, J., \& Kostera, M. (2010). Experiencing the shadow: Organizational exclusion and denial within experience economy. Organization, 17(2), 257-282.

Kociatkiewicz, J., \& Kostera, M. (2012). The speed of experience: The co-narrative method in experience economy education. British Journal of Management, 23, 474-488.

Kociatkiewicz, J., \& Kostera, M. (2014). Liquid organization. London: Routledge.

Laverie, D., Kleine, R. E., III, \& Schultz-Kleine, S. (1993). Linking emotions and values in consumption experiences: An exploratory study. In McAlister, L., \& Rothschild, M. L. Eds. Advances in consumer research. 20 (pp.70-75). Provo, UT: Association for Consumer Research.

Le Soir. (2010a). Unity in apathy / http://www.presseurop.eu/ en/content/news-brief/252641-unity-apathy $\rangle$ (accessed online: $15 / 06 / 2012)$.

Le Soir. (2010b). Ce pays a-t-il encore un sens? /http://www.presseurop.eu/en/node/237591〉 (accessed online: 15/06/2012).

Lin, C. Y. Y., \& Chen, M. Y. C. (2007). Does innovation lead to performance? An empirical study of SMEs in Taiwan. Management Research News, 30(2), 115-132.

Lincoln, Y. S., \& Guba, E. G. (1985). Naturalistic inquiry. Beverly Hills, CA: Sage.

Mishler, E. G. (2000). Validation in inquiry-guided research: The role of exemplars in educational practice. In B. M. Brizuela, J. P. Stewart, R. G. Carrillo, \& J. G. Berger (Eds.), Acts of inquiry in qualitative research (pp. 119-146). Cambridge, MA: Harvard Educational Review.

Novak, T. P., Hofmann, D. L., \& Yung, Y.-F. (2000). Measuring the customer experience in online environments: A structural modeling approach. Marketing Science, 19(1), 22-24.

Newell, S., Tansley, C., \& Wagner, E. L. (2008). The liminality associated with project teams: Exploring and explaining some of the problems of ES project implementations. CIS Proceedings 63: .

Noe, R. A. (2002). Employee training and development. New York, NY: McGraw-Hill.

Orlikowski, W. J., \& Baroudi, J. J. (1991). Studying information technology in organizations: Research approaches and assumptions. Information Systems Research, 2(1), 1-8.

Paulsen, N., \& Hernes, T. (2003). Managing boundaries in organizations-multiple perspectives. Houndmills: Palgrave/Macmillan.

Peirce, Ch. S. (1931/1958). In P. Weiss \& W. A. Burks (Eds.), Collected papers of Charles Sanders Peirce (8 vols). Cambridge: Harvard University Press.

Peters, T. J., \& Waterman, R. H. (1982). In Search of Excellence Lessons from America's Best-Run Companies. London: HarperCollins Publishers.

Peppers, D., \& Rogers, M. (1993). The one to one future: Building relationships one customer at a time. New York, NY: Bantam Doubleday Dell Publishing.

Pine, B. J., \& Gilmore, J. H. (1998). The experience economy. Harvard Business Review, 76(4), 97-105.

Pine, J. B. I., \& Gilmore, J. H. (1999). The experience economy: Work is theatre and every business a stage. Boston: Harvard Business School Press.

Prašnikar, J., Ferligoj, A., Cirman, A., \& Valentincic, A. (1999). Risk and managerial incentives in transition towards the market economy: The case of Slovenian enterprises. In J. Prašnikar (Ed.), Postprivatization behaviour of Slovenian enterprises. Ljubljana: Gospodarski vestnik.

Raz, A. E. (2003). The slanted smile factory: Emotion management in Tokyo Disneyland. In D. Harper \& H. M. Lawson (Eds.), The cultural study of work (pp. 210-227). Oxford: Rowman \& Littlefield Publishers. 
Reichertz, J. (2010). Abduction: The logic of grounded theory. In A. Bryant \& K. Charmaz (Eds.), The Sage handbook of grounded theory (pp. 214-244). London: Sage.

Ritzer, G. (1999). Enchanting a disenchanted world. Revolutionizing the means of consumption. Thousand Oaks, CA: Pine Forge Press.

Rottenburg, R. (2000). Sitting in a bar. Studies in Cultures, Organizations, and Societies, 6(1), 87-100.

Sanchez, A. M., Jimenez, J. V., Carnicer, P. D. L., \& Perez, M. P. (2007). Managerial perceptions of workplace flexibility and firm performance. International Journal of Operations and Production Management, 27(7), 714-734.

Schutz, A. (1963). 'Common-sense and scientific interpretation of human action'. In M. A. Natanson (Ed.), Philosophy of the Social Sciences (pp. 302-346). New York, NY: Random House.

Seale, C. (1999). Quality in qualitative research. Qualitative Inquiry, 5(4), 465-478.

Simpson, P. (2010). Engaging with the unknowable through narratives of personal experience. Journal of Organizational Change Management, 23(2), 173-179.

Spariosu, M. I. (1997). The wreath of wild olive: Play, liminality, and the study of literature. New York, NY: State of University of New York Press.

Stenbacka, C. (2001). Qualitative research requires quality concepts of its own. Management Decision, 39(7), 551-555.

Strauss, A. L. (1987). Qualitative analysis for social scientists. Cambridge: Cambridge University Press.

Strauss, A. L., \& Corbin, J. (1990). Basics of qualitative research grounded theory procedures and techniques. Newbury Park: Sage.

Sturdy, A. J., Schwarz, M., \& Spicer, A. (2006). Guess who's coming to dinner? Structures and uses of liminality in strategic management consultancy. Human Relations, 59(7), 929-960.
Sutton-Smith, B. (1997). The ambiguity of Play. Cambridge, MA: Harvard University Press.

Swan, J. E., Trawick, F. I., Jr., Rink, D. R., \& Roberts, J. J. (1988). Measuring dimensions of purchaser trust of industrial salespeople. Journal of Personal Selling \& Sales Management, 8: 1-9.

Tempest, S., \& Starkey, K. (2004). The effects of liminality on individual and organizational Learning. Organization Studies, 25(4), 507-527.

Turner, V. (1967). Betwixt and between: The liminal period in rites de passage. Forest of symbols: Aspects of the Ndembu ritual, Ithaca: Cornell Univrsity Press.

Turner, V. (1969). 'Liminality and communitas'. The ritual process: Structure and anti-structure, Chicago: Aldine.

Turner, V. (1982). From ritual to theatre: The human seriousness of play. New York, NY: PAJ Publications.

Van Maanen, J. (1979). The fact of fiction in organizational ethnography. Administrative Science Quarterly, 24(4), 539-550.

Van Maanen, J. (1988). Tales of the Field: On Writing Ethnography. Chicago: University of Chicago Press.

Van Maanen, J., \& Schein, E. H. (1979). Toward of theory of organizational socialization. Research in Organizational Behavior, 1: 209-264.

Verhoef, P. C., Lemon, K. N., Parasuraman, A., Roggeveen, A., Tsiros, M., \& Schlesinger, L. A. (2009). Customer experience creation: Determinants, dynamics and management strategies. Journal of Retailing, 85(1), 31-41.

Warren, S. (2012). Having an eye for it: Aesthetics, ethnography and the senses. Journal of Organizational Ethnography, 1(1), 107118.

Zabusky, S. E., \& Barley, S. R. (1997). You can't be a stone if you're cement: Reevaluating the emic identities of scientists in organizations. Research in Organizational Behaviour, 19, 361-404. 